Session 1520

\title{
Designing, Developing, and Implementing an Online Engineering Thermodynamics Course Using Web Technology
}

\author{
M.P. Sharma, Ph.D., Gary M. Fetter University of Wyoming
}

\begin{abstract}
While there has been extraordinary growth in development and delivery of accredited online degree programs and courses in many disciplines, the engineering field continues to lag behind and accredited online engineering degree programs continue to be virtually unavailable. In engineering education, the more prevalent trend is that of instructors and educators using Web technology for supplementing and enhancing traditional classroom teaching. The reason for the slow rate of growth in using this new technology for teaching entirely online courses in engineering is not apparent. In Wyoming, there is even a greater need for online delivery of basic engineering courses so that transfer students, most of who live in distant and remote areas, and other prospective students can prepare themselves prior to arriving on campus. In Spring 2000, with the sponsorship of the Engineering College and the School of Extended Studies, the lead author proposed and initiated a project to design, develop, and deliver a complete online course in Engineering Thermodynamics that would satisfy the University of Wyoming's requirement for the accredited degree in engineering. The authors, then, did research on developing a suitable pedagogical approach for effective teaching and learning using Web and online delivery technologies, particularly focused on the special nature, nuances, challenges, and needs related to the subject of thermodynamics. It is the first course ever to be offered fully online by the Engineering College at the University of Wyoming (to our knowledge, this also may be the first university accredited fully-online thermodynamics course offered on the Web that satisfies undergraduate engineering degree requirements).
\end{abstract}

Online teaching and learning offers many benefits and opportunities to learners and educators; however, it also offers new challenges and unique considerations for developers, educators, and learners. This paper presents and addresses many of the pedagogical, technical, attitudinal, and environmental challenges encountered by the educators in the process of developing, designing, and implementing an engineering course for online delivery at the University of Wyoming.

\section{Introduction}

With the advent of Web and Internet technology, engineering education is entering a new and challenging age. One of our biggest challenges is integrating online technology and assessing the outcome of our engineering curriculum. As most of us know, the Internet/World Wide Web (WWW) is a powerful tool, which provides unprecedented opportunities to expand and enhance teaching/learning resources and environments. The information created is accessible on demand anytime, anywhere. Recent advances in technologies for building and using knowledge bases and for creating and developing Multimedia rich information have made teaching complete Webbased courses a reality. Increasing growth of Web-based educational materials clearly points to 
the trend of using Web technology as an alternative mode of course delivery in modern education. In particular, the World Wide Web (WWW) can be used with great advantage in teaching high enrollment courses as well as distance education ${ }^{1}$. If the current trend continues, online technology is ready to dominate the way education is conducted in future. As John Stukel, President, University of Illinois states, the vision of many of the universities involved in online teaching includes emphasis in learning "beyond the bounds of time and space." All of the potential benefits of delivering online learning come with new considerations and challenges. The purpose of this paper is to present the challenges encountered by educators in the process of developing, designing, and implementing an online engineering course at the University of Wyoming

\section{Background}

As a teacher of thermodynamics, the primary author has had the responsibility of developing and implementing a variety of tools and strategies for improving the teaching and learning of thermodynamics. This paper outlines a project that probes new directions in teaching engineering courses particularly engineering thermodynamics using the Web-based online technology. While new research examining online courses in many disciplines continues to increase, there are few online Engineering courses and therefore little research. Perhaps the inability of existing online technologies to adapt to the complexities of teaching engineering courses as compared to other disciplines has contributed to the fewer number of online courses. At the beginning of the Fall 2000 semester, the College of Engineering at the University of Wyoming approved offering of an online thermodynamics course in Spring 2001. Since this would be the first entirely online engineering course ever offered by the college, the project is being organized into two stages. The first stage was to design and develop the online course. During this stage, Web technologies were introduced into the traditional classroom-based thermodynamics course to help facilitate transition to an online environment and provide a context for design and development of the online course. The second stage, which is currently in process, is to deliver the online thermodynamics course during the Spring 2001 semester.

\section{Literature Review}

While there is little literature specifically related to online teaching of engineering thermodynamics, there is a tremendous amount of literature available about teaching thermodynamics in the traditional classroom environment. In the field of engineering education and among students and alumni of engineering, thermodynamics course carries a reputation of being frustrating, confusing, and demanding. At best, most consider it difficult to acquire mastery of concepts, principles, and procedures of thermodynamics. Many accomplished teachers of engineering thermodynamics have experimented and researched on novel approaches for teaching thermodynamics more effectively ${ }^{2}$. The adoption of new Web-based pedagogical methods and approaches for teaching thermodynamics leads to concerns with existing assessment methodologies to evaluate teaching and learning. There are a variety of opinions in face of skepticism and resistance to change and enthusiasm for something that is new. These views range from negative to positive. 
- "I am uneasy about classes in which students learn entirely from home in front of a computer screen, with no face to face reaction with other students and instructors - Justice R.B. Ginsberg"3

- As Associate Professor John Regalbuto, Chemical Engineering, University of Chicago points out, the "quality of teaching suffers when students and professors do not interact in person."

- Assoc. Professor Sherry McConnell, Histology, Colorado State University observed, that "the results were so astounding, it was clear to me students were doing better with the online class."

- "Welcome to the future of learning" - Unext Website. ${ }^{3}$

- "(online teaching) is ground-breaking distance learning enterprise" -Columbia University. ${ }^{3}$

Kovalik $^{4}$, Felder ${ }^{5}$, Catalano $^{6}$, Clough $^{7}$, Baher $^{8}$, Loacker $^{9}$, McGourty $^{10}$ have addressed these concerns in their research. Their papers provide a good resource base for researching and designing a modern and appropriate assessment plan for this course. Based on the review of published literature, it is conjectured that online engineering thermodynamics course could help in improving engineering and science education. It can provide a powerful motivating context for learning fundamental and applied principles, allowing students an interest that could prove invaluable for instruction in engineering and could better motivate their interest in learning.

\section{Course Learning Objectives}

The following learning objectives were identified for the design and development of the online engineering thermodynamics course:

Unit 1 : After reading and studying the materials of this chapter the student should be able to:

- Define thermodynamics as (a) the science of change, and (b) the study of energy and entropy, and the conversion of energy from one form to another.

- Define and learn some of the initial important concepts and vocabulary and units of measurements: System, Control Volume, Property, Equilibrium, State, Process, Cycles, point and path functions, pressure, temperature...

- Use the observable external characteristics that are known as properties to describe a system.

- Learn and use gage and absolute pressure definitions and applications.

- Understand the "State Postulate" and its usefulness.

- Define pressure as property and learn its units, dimensions, and conversions from one unit to another. Understand difference between gauge and absolute pressures.

- Use the concept of pressure in both English and SI units. Gage and absolute pressure definitions are important ideas that are necessary in engineering applications.

- Use the concept that fluids exert pressures that can be expressed in terms of the height and specific weight of the column of fluid. 
- Define temperature as a property and its relationship with Zeroth Law of Thermodynamics. Learn about units and dimension of temp. Establish and convert from one system of temperature measurement to another, and understand the four methods of measuring temperature.

- Use both the English and SI systems of units

Unit 2: After reading and studying the materials of this chapter the student should be able to:

- Understand the concept of phase and components, and distinguish among the three phases of matter.

- Understand phases of a pure substance, and the phase change process of a pure substance (water).

- Describe the various graphical representations of the properties of steam, especially the temperature-specific volume, pressure-specific volume properties diagrams.

- Understand and use the fact that the vaporization process is carried out at constant temperature and that less heat is required to vaporize a unit mass of water as the pressure is raised.

- Define the state that is known as the critical state.

- Understand and use the nomenclature used in the Steam Tables.

- Understand the use of the triple point as the reference state for zero internal energy and enthalpy (and later zero entropy).

- Define the term quality, and use it to determine the properties in the wet region.

- Obtain the properties of steam in the sub-cooled, saturated, and superheated states.

- Represent state paths for various processes on these property diagrams.

- Be aware that industry uses computer systems to determine the properties of steam either by use of equations or by use of readily available commercial programs, and be able to use the enclosed computer disk to obtain the properties of steam in both SI and English units.

- Understand the term ideal as applied to gases.

- Express the units of the gas constant in both SI and English systems, and use the molecular weight to determine the gas constant for a given gas.

- Use ideal gas equation of state (EOS) and understand its limitations.

- Real Gases and Deviation from ideal gas behavior.

- Understand and use Compressibility Factor method for real gases.

- Become familiar with other EOS.

Unit 3. After reading and studying the materials of this chapter the student should be able to:

- State the definitions of work, energy, and heat.

- Use the fact that both work and heat are forms of energy in transition. 
- Apply the convention that heat into a system is to be taken as a positive quantity. This convention is taken from the customary power-producing cycle in which heat into a system is used to generate useful work.

- Use the fact that the work of a quasi-static, non-flow system is the area under the pressure-volume curve.

- State the first law of thermodynamics, or energy conservation, for non-flow systems.

- Apply the first law of thermodynamics to several non-flow systems, such as the adiabatic system, the constant-volume system, and the constant-pressure system.

- Define the term specific heat, and show that the specific heats at constant volume and cons Calculate the average specific heat of a gas for a gas over a temperature range.

- Calculate internal energy and enthalpy changes for ideal gases, solids, and liquids using specific heat values.

- Calculate the average specific heat of a gas for a gas over a temperature range.

Unit 4: After reading and studying the materials of this chapter the student should be able to:

- Differentiate between a non-flow or closed system and a flow or open system (control volume).

- Differentiate between Steady State and Unsteady State processes.

- Derive and apply the Mass Conservation (continuity) equation in its several forms to express the conservation of mass in (a) closed system and in (b) a steady-flow system.

- Understand the origin of the term flow work, and apply it to a flow system.

- Define enthalpy, and show that it is a property and therefore does not depend on whether a system is a non-flow or flow system.

- Derive the energy equation from the first law of thermodynamics for a steadyflow system.

- Apply the first law of thermodynamics to the analysis of the steam or gas turbine, pipe flow, boilers, nozzles, throttling, heat exchangers, and the filling of a tank.

- Show how the throttling process can be used to determine the quality of wet steam.

Unit 5 : After reading and studying the materials of this chapter the student should be able to:

- Understand the concepts of thermal energy reservoirs.

- Understand that work can be converted into heat but that the conversion of heat into useful work may not always be possible.

- Define a heat engine as a continuously operating system across whose boundaries flow only heat and work.

- Define a thermodynamic refrigerator and heat pump. 
- Define thermal efficiency as the ratio of the useful work delivered by a heat engine or cycle to the heat input to the engine or cycle.

- Define the COP for refrigerators and heat pumps

- Understand what is meant by the statement that a reversible process is any process performed so that the system and all its surroundings can be restored to their initial states by performing the process in reverse.

- State Kelvin-Planck and Clausius statements of the second law of thermodynamics.

- Understand the concept of Perpetual Motion machines.

- Understand that all natural processes are irreversible, and cite some of the effects that cause irreversibility.

- Explain the four processes that constitute the Carnot cycle.

- Deduce from the Carnot cycle three important general conclusions concerning the limits of the efficiency of a heat engine.

Unit 6 : After reading and studying the materials of this chapter the student should be able to:

- Define a new property that is introduced in this chapter that we call entropy.

- Understand that entropy is also a measure of the unavailability of energy that occurs in an irreversible process.

- Calculate the change in entropy for a process in which there is a temperature change, such as the mixing of two fluids.

- Understand that the entropy of an isolated system increases or, in the limit, remains the same (Entropy increase principle)

- Calculate the entropy changes of pure substances (water using steam tables).

- Write the general expression for the entropy change of an ideal gas from which the equation of path for an isentropic process is obtained.

- Use the Gas Tables to solve gas processes.

- Derive relations for constant-volume, constant-pressure, constant-temperature, isentropic, and polytropic processes.

- Think of the area under the pressure-volume diagram as the work of compression or expansion and the area behind the pressure-volume diagram as the work of the compressor or expander.

- Understand the shortcomings of the Bernoulli equation.

- Understand and use the isentropic efficiencies of pumps, compressors, turbines, nozzles.

Unit 7: After reading and studying the materials of this chapter the student should be able to:

- Differentiate between internal-combustion and external-combustion heat engines.

- Describe the sequence of events in the four-stroke and two-stroke cycles.

- State the assumptions made in air-standard cycle analyses.

- Sketch the ideal Otto cycle on both p-v and T-s diagrams.

- Show how an actual cycle differs from the ideal Otto cycle. 
- Derive the expression for the efficiency of the ideal air-standard Otto cycle, and show that it is a function only of the compression ratio.

- Sketch the ideal Diesel cycle on both p-v and T-s diagrams.

- Show that for the same compression ratio, the efficiency of the ideal Otto cycle is greater than the efficiency of the ideal Diesel cycle.

- Understand why the Diesel cycle can be operated at higher compression ratios than the Otto cycle.

- Sketch the ideal Brayton cycle on both p-v and T-s diagrams.

- Show that for the same compression ratio, the Brayton and Otto cycles have the same thermal efficiency.

Unit 8: After reading and studying the materials of this chapter the student should be able to:

- Understand the definition of the term cycle, and differentiate between gas and vapor cycles.

- Recall that our conclusions regarding the Carnot cycle were independent of the working fluid used in the cycle.

- Sketch and analyze the elements of the simple Ideal Rankine cycle.

- Perform the energy analysis of a simple Ideal Rankine Cylcle based power plant.

- Calculate the efficiency, the heat rate, and back-work ratio, and compare with Brayton cycle.

- Conclude that for the same pressures, the efficiency of the Rankine cycle is less than that of a Carnot cycle.

- Understand the difference between a real Rankine cycle and an Ideal Rankine cycle, and how to calculate performance of a real Rankine cycle.

\section{Course Design and Development}

In the beginning, it was important to consider the systems in place for instructional support as well as the software and hardware tools supported on campus. At the University of Wyoming, courses taught entirely online are coordinated and supported through the Outreach School while traditional courses using technology are supported through the Center for Teaching Excellence. In addition, the Outreach School has contracted with eCollege.com to provide instructional support, server hardware, and eCollege software while the Center for Teaching Excellence uses an internal server running WebCT software.

After approval of the online course, the lead author met with instructional design staff of eCollege and the Engineering Science Articulation Committee members. These meetings and discussions have provided some very useful input and larger perspectives of the project.

In order to become familiar with the software tools and to gain experience using these tools in teaching, Web-based learning technology was integrated into the traditional on-campus thermodynamics course during the Fall 2000 semester. While the course objectives of the online course as compared to the course objectives of the traditional classroom-based course remained constant, the interaction in the pedagogical process would be achieved only by effective use of 
technology. The presence of interaction in both course design and media are paramount in order to achieve quality instruction. Our goal was to achieve the quality critical interaction that Markwood and Johnstone identified as triggered by the following four different types of interactions, each made possible by somewhat different technologies. ${ }^{11}$

1. Interaction with media--individual students scrutinizing textbooks, videotapes or other course materials.

2. Interaction with resources--individual students or groups collaborating with the same or similar tools as those used by the professionals, for example word processors, electronic libraries, laboratories or studios.

3. Interaction with experts--students conversing with the instructor, other students or content experts in real time.

4. Interaction through electronically or digitally sharing the results of newly formed knowledge over periods of days or hours.

The course was divided into eight units with each unit basically representing a chapter of the textbook. Various content components were organized using the WebCT path editor tool creating opportunities for students to interact with course materials. We posted lecture notes, chapter summaries, homework examples, and PowerPoint presentations so that students could easily access information and use the materials in a way that is more closely associated with their individual learning style. For example, rather than having only a lecture to attend, a student who tends to best learn visually could revisit a specific graph or slide that was discussed in class on the Web site to help clarify concepts. .

Since most people read by scanning Web pages and prefer information organized into single pages rather than long, scrolling pages, our goal was to organize our course materials so that it could be most easily retrieved by students. ${ }^{12}$ The WebCT path editor tool allowed us to easily organize navigation into frames so that students would see all of the materials for each chapter on one screen. The existing lecture notes, PowerPoint presentations, and other materials in form of Microsoft Word and PowerPoint files were simply saved in html format and transferred to the Web site on the university WebCT server. Once the files were transferred, they were added to the student display using the easy menu-driven commands of the WebCT path editor tool.

The synchronous WebCT Chat Tool was used to create forums for communicating between instructor and students as well as for communicating among students. While this real-time collaboration tool would be a more widely used pedagogy for communicating in the online course in the Spring, the WebCT Chat tool would supplement classroom discussions and provide a new mechanism for students not usually eager to talk in the classroom for whatever reason. The synchronous WebCT chat communication tool was used during the semester for communicating with students during scheduled office hours and on two other occasions for class meetings. During the two "virtual" class meetings, students were given several open-ended questions to discuss and participation was required. Focusing the open-ended question on the application of engineering concepts to real-world situations worked best in creating the foundation for effective, high-quality discussions. 
The WebCT Bulletin Board, an asynchronous communication tool, was also used to create forums for communicating between instructor and students as well as for communicating among students. In many ways more useful than the WebCT Chat Tool, the WebCT Bulletin Board allowed students to read messages and respond to messages on their own time. Messages were organized into threaded discussions so students could read and respond to specific messages creating a thread-like trail of related information. While this tool would be the foundational pedagogy for communicating in the online course in the Spring, it proved beneficial in encouraging student discussion and creating cooperative learning environments that might not have occurred only during the limited classroom time. The WebCT Bulletin Board Tool was used primarily for threaded discussions relating to concepts and information from readings or class discussions; however, unlike in the classroom, the WebCT Bulletin Board tool allowed students to read postings and draw conclusions before responding. This allowed students the time to think through information and build confidence they might individually need to participate in a discussion. Students shared information and knowledge over periods of hours and days creating a digital record that they could refer to throughout the course in the same way that Markwood and Johnstone identified.

The WebCT navigation tools and communication tools were easy to use and did not require significant training to use. While the text-based content initially provided online was easily converted to html format, future interactive content components will require more planning. For example, during this initial stage of the project, interactive content components to be used in the completely online course were collected and designed. The student benefits of being able to visually explore complex engineering concepts such as Ideal Gas Law will come with additional considerations. Some of the java-based components or modules developed using Macromedia Authorware will require specific browser settings or free vendor plug-ins. Ensuring that the necessary support is available for instructors and students is essential.

In addition to the WebCT tools used to foster communication and interaction, the WebCT Quiz Tool was used for assessment and the WebCT Gradebook Tool for course management. Both of these tools were used in the online course in the Spring but were beneficial to students taking the hybrid course. The WebCT Quiz Tool allowed for questions to be randomized and automatically graded except for essay or short answer questions, which required instructor review and comment. While these tools differed in terms of specific execution from the eCollege software used in the online course, the general objective remained constant.

\section{Assessment and Evaluation}

The few research studies that exist focusing on student assessment in online teaching-learning are much debated. There is a need for designing assessment methods for online activities because of new dimensions, directions, and paradigms of the online teaching-learning environment. The primary author, together with researchers at Texas Tech University, has begun a three-year project, funded by the National Science Foundation, to develop an assessment process for computer-based learning of engineering thermodynamics courses. In this current online course, we used multiple evaluation techniques similar to conventional classroom methods. In addition to grading and evaluation of online tests and homework assignments, the 
quality of participation in the synchronous (Chat Room) sessions and the asynchronous (Bulletin Board) sessions was evaluated along with traditional classroom participation.

Like the traditional classroom-based course, the online course is organized into eight units. After all of the teaching and learning activities are completed for a unit of the course, a timed test is administered online and graded electronically. Grades are posted electronically in the online gradebook after any written answers are graded and the test is reviewed for accuracy. Homework assignment problems are graded by the teaching assistant or the instructor and entered in the online gradebook.

A threaded discussion also accompanies each unit of the course. A set of questions representing the core concepts and procedures of the unit are posted as a thread to the bulletin board. Students are given deadlines to post responses to the questions and another deadline for participating in discussion among other students in the learning community. Grades are entered into the online gradebook after this second discussion activity is completed.

Each student is required to participate in a synchronous chat session with the instructor for each unit of the course. Several chat sessions are offered for each unit to accommodate different individual schedules. The quality of participation, questions, comments, and discussion is graded and distributed in the online gradebook.

The eCollege software also keeps a record of the frequency that a student visits the different sections of the course including the unit course materials. This activity log is a good indicator of how active an individual student has been in the course but material still needs to be reviewed for quality.

\section{Conclusions}

The development, implementation, evaluation, enhancement, and new implementation of components and modules of any online course is a continuing process of evolution towards perfection, especially in view of the fast changing Web tools and technologies. This online thermodynamics course is no exception. Over the past year, all of the essential components of a Web-based thermodynamics course were designed, developed, and tested for three different teaching approaches for the course: (1) a traditional classroom-based lecture course, (2) an entirely online course, and (3) a hybrid-combination of the two approaches with approximately equal emphasis on both online and classroom-based activities. These components were implemented differently in each of the three approaches of teaching the course. Some of our conclusions are interim and preliminary in nature because the data on some aspects, activities, and objectives of the project are continuing since the online course is only at the half-way point as of the writing of this paper.

Here are our conclusions to this point:

- Though the ideas and benefits of Web-based and online courses seem obvious, the details and skills necessary to create them can require time to learn; 
however, the possibilities of improving teaching-learning effectiveness by using these technologies is what is very exciting.

- Development and teaching of an online course in Thermodynamics needs consideration of unique pedagogical and technical characteristics. Pedagogically, the issue of effective teaching approaches (between Generalized approach versus Building block approach) needs to be decided, which will impact the design of online course content and delivery. Technically, special needs for course tools and techniques arise in implementing intensive features of complicated engineering graphics, mathematical equations, complex three-dimensional images, animations, and visualizations. Platforms like WebCT and eCollege have limited capabilities in these areas and more advanced development software such as Authorware, Flash, and Java need consideration.

- The most successful students in the online thermodynamics course seem to be those students who are more self-motivated and self-directed who have a preference for self-paced learning rather than directed learning. The online course development and teaching initiative needs a new thinking and approach and should not be planned with the "offline thinking hat" on.

- Since it was a cross-disciplinary project, leadership and support at all levels are required including technical staff, teachers, administrators, deans, department heads, from the Engineering College, Outreach School, and appropriate support units on campus. In face of skepticism and resistance coupled with few tangible rewards for faculty involvement, the above factors become even more critical for the success of an online course project.

- The most efficient way to implement the online thermodynamics course was to follow a stepwise (two-step) implementation plan, i.e. first to implement Web-based components in a Hybrid teaching approach, and then, during the following semester, implement the entirely online course.

- The most efficient way to design and develop an online thermodynamics course is to start with the essential content elements and then, with the use of more advanced tools, work to improve and added more interactive content components.

- Based on student surveys and teaching evaluations in two consecutive semesters of teaching (one without the use of online component, and the other with Hybrid approach), we found that the effectiveness of the hybrid course using online technologies was significantly better as evaluated by the students.

- Online teaching creates a different paradigm for analyzing curricular performance and student assessment and evaluation.

\section{Where to Go from Here: Future Enhancement and Recommendations}

Many tools and technologies, such as WebCT, eCollege, Blackboard, etc., that are used in the design, development, delivery, and evaluation of online courses are changing and being upgraded more quickly than online courses themselves. Development and delivery of an engineering course, like Thermodynamics, will benefit most in the future by using cutting-edge 
software tools and techniques because online engineering courses present complex challenges for delivering education than traditional classroom-based courses.

Here are some thoughts, ideas, and research and development activities needed to increase the interactions that Markwood and Johnstone identified which will significantly advance the teaching-learning effectiveness of this course:

- Implementing real-time streaming media technology to provide audio and video multimedia components

- Integrating synchronous electronic White Board tools to facilitate online discussions of concepts and ideas

- Improving content graphics and visuals used in unit course materials

- Providing student controlled interactive content components using Flash, Authorware, Java, etc. to allow students to learn by exploring complex concepts such as Ideal Gas Law and Energy and Entropy Balance Equations

\section{References and Bibliography}

1. Jong, I., et. al., (1999), “Simole Scripts to Produce Interactive Web-Based Tests with Immediate Feedback”, JEE, October.

2. O'Connell, J. "Thermodynamics: A structure for teaching and learning about much of reality" Chemical Engineering Education, Spring 1993.

3. Gomory, R.E., "Internet Learning: Is it real and what does it mean for universities?" Sheffield Lecture, Yale University, Jan. 11, 2000.

4. Kovalik, C.L., et.al., (1999), “The process/Outcome Evaluation Model: A conceptual Framework for Assessment", J. Educational Technology systems, vol. 27 (3).

5. Felder, R.M., et. al., (1988), "Learning and Teaching Styles in Engineering Education", JEE, vol 7, no. 7.

6. Catalano, G.D., (1995), "Some Ideas on Teaching of Engineering Science: A Student Centered Approach", JEE, no. 1.

7. Clough, M.P., et. al., (1999), "Improving Engineering Education: A Research-Based Framework for Teaching", JEE, October.

8. Baher, J., (1999), “Articulate Virtual Labs in Thermodynamics Education: A Multiple Case Study”, J. Engineering Education (JEE), October.

9. Loacker, G. et. al., (1993) "Creating a Culture Where Assessment Improves Learning” in T. Banta (ed.) Making a difference: Outcomes of a Decade of assessment in Higher Education” Jossey-Bass.

10. McGourty, J. (1999), Four Strategies to Integrate Assessment into the Engineering Educational Environment, JEE, October.

11. Markwood, R. and Johnstone, S. eds.(1994). New Pathways to a Degree: Technology Opens the College and New Pathways to a Degree: Seven Technology Stories. Boulder, Colorado: Western Interstate Commission for Higher Education.

12. Markes, J. and Nielsen, J., (1997), "Concise, SCANABLE, and Objective: How to Write for the Web" URL: http://www.useit.com/papers/webwriting/

\section{M.P. Sharma}

M.P. Sharma is a Professor of Chemical Engineering at the University of Wyoming. He also serves as the codirector of Environmental Engineering Graduate Studies Program (Interdisciplinary). He worked in industries for over 5 years before joining the faculty at University of Wyoming in 1982. He graduated with Ph.D. in Mechanical Engineering from Washington State University in 1977. 


\section{Gary Fetter}

Gary Fetter is currently Instructional Computing Coordinator for the Center for Teaching Excellence at the University of Wyoming. He received his MBA in Management Information Systems from The Ohio State University and has spent the past 15 years working with hardware and software technology in a wide variety of educational and business environments. 